American Journal of Applied Sciences 9 (6): 890-893, 2012

ISSN 1546-9239

(C) 2012 Science Publications

\title{
Adhesion and Hardness Evaluation of Modified Silicone-Dammar as Natural Coating Materials
}

\author{
Zakaria, R. and A.H. Ahmad \\ Institute of Science, Faculty of Applied Sciences, \\ Universiti Teknologi MARA 40450 Shah Alam, Selangor, Malaysia
}

\begin{abstract}
Problem statement: Dammar is a natural resin that used anciently in varnish production. The use of dammar natural resin in coating is limited by undesirable properties for application in coating where it is considered very brittle. Due to dammar's brittle nature, an aged dammar coating can be easily scratched or abraded. Approach: Dammar natural resin could be modified into SiliconeDammar by using a solvent in order to improve the coating's mechanical properties. The modified Silicone-Dammar (SD) was coated on aluminum q-panel and adhesion was evaluated using cross hatch test, impact test and pull off test, while the hardness of coating was investigated by nano-indentation test. Results: Results from cross hatch test, impact test and pull off test show that coating material with $15 \%$ wt. of dammar (SD15) was the optimum composition which exhibits good adhesion of modified Silicone-Dammar to the metal substrate. SD15 also could be considered as a soft and flexible polymer coating with hardness value of $1.624 \mathrm{GPa}$ after undergoing the nano-indentation test. Conclusion: A modified Silicone-Dammar coating system with varied compositions of dammar has been prepared and adhesion and hardness have been evaluated. It is found that $15 \%$ wt. of dammar in the coating material (SD15) exhibits good adhesion to aluminum substrate and soft and flexible in nature.
\end{abstract}

Key words: Modified silicone-dammar, varied compositions, coating material, coated on aluminum, aluminum substrate, aluminum q-panel, based resins, nano-indentation test, dow corning corp

\section{INTRODUCTION}

Dammar resin is one of the plant resin that can be found abundantly in tropical forest of Malaysia. It can be bled from Dipterocaupocea sp. of tree and being used in ancient time as varnish (Perera, 1996). Previously we have reported that dammar and acrylic polyol were mixed to form a modified resin (Omar and Ahmad, 2009) and it was found that the coating system with a composition of $35 \%$ wt. of dammar showed the best adhesion performance when the crosshatch adhesion test was performed.

Among the polymer resin, silicone is well known as a heat resistance resin. The formation of a new modified binder of silicone and dammar designated as $\mathrm{SD}$, may produce a new era of modified dammar resin which can reduce the use of synthetic binder with improved properties and more environmentally friendly. Recently, the used of bio based resins and coatings has been widely discussed in the International Coatings Industry Letter by SpecialChem and can be found in the literature (ILSC, 2011; Pan and Webster, 2011).
The main objective of this study is to evaluate the adhesion performance of SD resin as natural resin by using adhesion test and the hardness by nano-indentation hardness test. The modified SD coating is prepared and proofed on aluminum panels. The cured SD coating are subjected to cross hatch test (ASTM D3359), impact test, pull off test and nano-indentation test.

\section{MATERIALS AND METHODS}

In this study silicone and dammar were used in preparing modified Silicone-Dammar (SD). Silicone with 60 wt $\%$ of solid content was used and purchased from Dow Corning Corp. Ltd and raw dammar was purchased from local sources. Dammar was ground to sieve out the plant skin residue. Xylene with laboratory grade was used as the solvent. SD coating materials were prepared according to the compositions shown in Table 1. SD mixtures were coated on aluminum q-panel surfaces by using spin coater at a low speed and conventionally dried at room temperature for one week.

Characterization of samples:

Corresponding Author: Zakaria, R., Institute of Science, Faculty of Applied Sciences, Universiti Teknologi MARA 40450 Shah Alam, Selangor, Malaysia 
Am. J. Applied Sci., 9 (6): 890-893, 2012

Table 1: Compositions of SDx coating system

\begin{tabular}{lcc}
\hline Sample & Silicone resin (wt \%) & Dammar resin $(\mathrm{wt} \%)$ \\
\hline SD0 & 100 & 0 \\
SD5 & 95 & 5 \\
SD10 & 90 & 10 \\
SD15 & 85 & 15 \\
SD20 & 80 & 20 \\
SD25 & 75 & 25 \\
SD30 & 70 & 30 \\
SD35 & 65 & 35 \\
SD40 & 60 & 40 \\
SD45 & 55 & 45 \\
\hline
\end{tabular}

Cross hatch test: Is a popular and widely used method to measure adhesion. This test is used in coating industry in general and gas and oil pipeline particular. The test was conducted according to ASTM D3359-83, using a cutter with six blades that make $2 \mathrm{~mm}$ square lattice cuts width of the coating film. The cuts were made through the coating film with steady motion using just sufficient pressure on the knife. A specially manufactured and design tape was placed on the cross cut surface for one or two seconds before it was pulled off. The panel was placed under an illuminated magnifier to inspect any delamination of the film. The classification of the delaminate film and the description of the tester was based on the criteria and standard stipulated in the ASTM D 3359-83 (Omar and Ahmad, 2009; Zakaria and Ahmad, 2009).

Impact test: is a widely used method to evaluate the ability of the coating to resist cracking when the deformation is applied rapidly. A weight of $1 \mathrm{~kg}$, was dropped down for $1 \mathrm{~m}$ through a guide tube onto the hemisphere indenter that rest on the coated panel surface. The damage was observed using surface microscope.

Pull off test: Is conducted using the flat face of dolly (stub) adhered to the coating surface and by applying pressure the actuator slowly lifted the dolly off from the surface. The maximum pressure needed to lift the dolly was read on the system's pressure gauge.

Nanoindentation: Using Berkovich type diamond with serial number: B-J0714.07.08 was used to penetrate the SD coating (Car et al., 2009; Zhili et al., 2004). The specimen was placed on friction table. Indentation force and together with indentation depth were obtained and the hardness of the coating was measured using the hardness Eq. 1:

$$
\mathrm{H}_{\mathrm{v}}=1.8544 \times \frac{\mathrm{P}}{\mathrm{D}^{2}}
$$

Where:
$\mathrm{P}=$ The load in $\mu \mathrm{N}$

$\mathrm{D}=$ The depth of the indent in $\mathrm{nm}$

\section{RESULTS}

Cross hatch: Was used to investigate the adhesion of SD coating. Table 2 shows the classified and description of surface morphology variation of SD coating at different composition of dammar. As the concentration of dammar increase from 5-15 wt. \% the coating surfaces are smooth with no flaking. Small flakes can be seen when the addition of Dammar has increase to 20 and 30 wt. \%. Further addition of dammar resulted in severe flaking.

Impact test: Was performed on the coating having thickness in the range of $100-200 \mu \mathrm{m}$. from Table 3 it can be seen that dammar content from 5-20 wt. \% exhibit smooth dented surface while radial cracking can be seen in SD coating with 25-30 wt. \% of dammar. The addition of dammar more than $30 \mathrm{wt}$ \% resulted in severe fractured in the coated samples. This attributes to brittleness and crystalline nature of natural dammar.

Pull off test is a further test to observe the adhesion of the coating. Figure 1 shows the amount of force and time required to detach the modified SD with varied compositions from the aluminum substrate. It can be seen that from Fig. 1 the amount of dammar content in the range of 5-15 wt. \% requires more force to pull out the dolly from the substrate. It takes $27 \mathrm{~s}$ and large pressure of 201 Psi to lift the dolly from the substrate for modified SD with 5 wt. \% Dammar. The modified coating with 15 wt. \% of Dammar also shows considerably good adhesion where a force of $180 \mathrm{Psi}$ is required to lift the dolly in $24 \mathrm{~s}$. When Dammar content has increased to $20 \mathrm{wt} \%$ the adhesion become low and detachment become easier since less force (140 Psi) is required to lift the dolly in a short period of time that is $5 \mathrm{sec}$.

Figure 2 depicts the hardness value of modified SD coating materials. Results from nano-indentation test reveals that the $5 \mathrm{wt}$ \% (SD5) and $15 \mathrm{wt}$. \% (SD15) of dammar are soft polymer coating with hardness value of 4.132 and $1.624 \mathrm{GPa}$ respectively and make these modified SD coatings are more flexible for aluminum substrate. While $10 \mathrm{wt}$. \% of dammar content gives hardness measurement of $28.533 \mathrm{GPa}$. The coating becoming harder $(25.68 \mathrm{GPa})$ again when $30 \mathrm{wt}$. \% (SD30) of dammar added. 
Table 2: Compositions of SDx coating system $\mathrm{Wt} \%$ of dammar Test image Classification and description

SD45 (45\% Dammar) OB: The flaking of the coating cannot even be classified by classification. Faking is worse than grade IB $(15-65 \%$ of the grid is affected)

SD40 (40\% Dammar) 2B: The coating has faced along the edges of the cuts partly or wholly in large ribbon or it has area significantly greater than $15 \%$ but greater than $35 \%$

SD35 (35\% Dammar) 2B: The coating has faced along the edges of the cuts Partly or wholly in large ribbon or it has area significantly Greater than $15 \%$ but greater than $35 \%$

SD30 (30\% Dammar) 3B: Small flaked have detached at intersections affection but more than approximately 5\% of the area

SD25 (25\% dammar)

3B Small flaked have detached at intersections affection but more than approximately $5 \%$ of the area

SD20 (20\% Dammar)

3B: Small flaked have detached at intersections affection but more than approximately $5 \%$ of the area

SD15 (20\% dammar)

5B: The edges of the cuts are completely smooth none of the squares of the lattice is detached SD10 (10\%

Dammar)

5B: The edges of the cuts are completely Smooth none of the squares of the lattice is detached

SD5 (5\% Dammar)

5B: The edges of the cuts are completely Smooth none of the squares of the lattice is detached

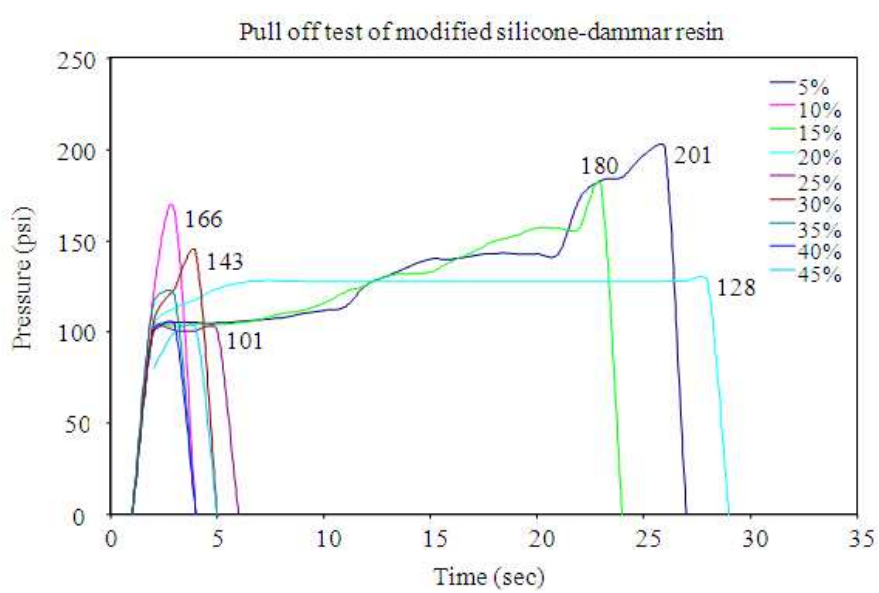

Fig. 1: Pressure versus time for modified SD coating with various compositions of dammar

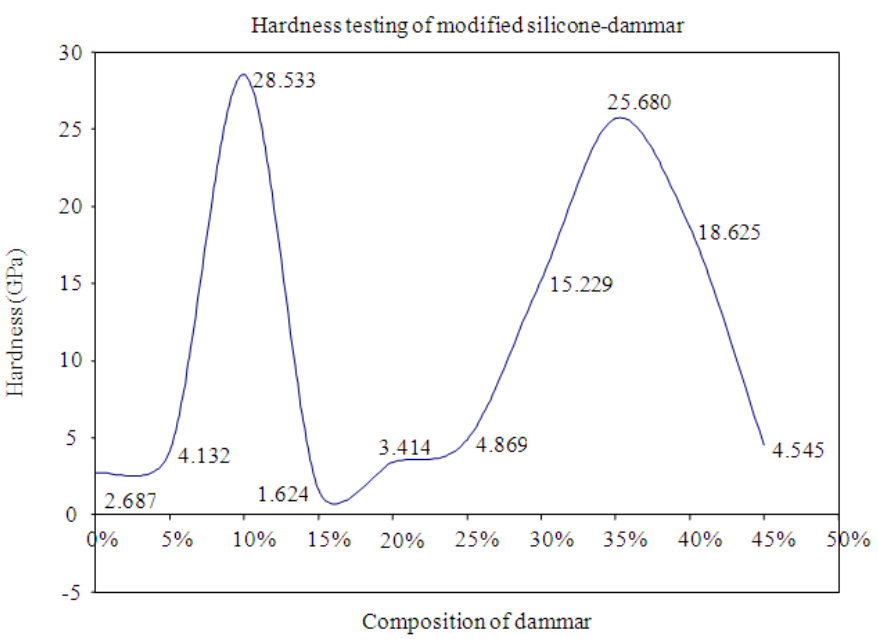

Fig. 2: Hardness versus various amount of dammar composition in modified SD coatings 
Am. J. Applied Sci., 9 (6): 890-893, 2012

Table 3: Pictures of the damaged/dented area of the SD coated substrate after impact test

\begin{tabular}{llllll}
\hline Sample & $\begin{array}{l}\text { Binder } \\
(\text { wt } \%)\end{array}$ & $\begin{array}{l}\text { Picture } \\
\text { captured Sample }\end{array}$ & $\begin{array}{l}\text { Binder } \\
\text { (wt \%) }\end{array}$ & $\begin{array}{l}\text { Picture } \\
\text { captured }\end{array}$ \\
\hline SD45 & 45 & & SD20 & 20 & \\
SD40 & 40 & SD15 & 15 & \\
SD35 & 35 & SD10 & 10 & \\
SD30 & 30 & SD5 & 5 & \\
SD25 & 25 & 0 & SD0 & 0 & \\
\hline
\end{tabular}

\section{DISCUSSION}

Results obtained from cross hatch test, impact and pull-off test were combined to evaluate the adhesion of modified SD coating. The modified SD coating with composition of dammar in the range of 5-15 wt. \% observed to strongly adhere to the substrate. Dammar can harden the Silicone resin coating. The optimum composition that can be added is $5-15 \mathrm{wt} \%$ as the cross hatch test showed the good result of it. A smooth dented showed by this optimum composition in impact test meaning that the dried coating were flexible and resist to impact action. While, this optimum composition coating also required the highest force to pull it off at the range of 180-240 Psi.

This could be due to the fact that adhesion of SD coating increases with the increase of double bond $\mathrm{C}=$ $\mathrm{O}$ that can be found in dammar (Zakaria and Ahmad, 2009), hence helped to increase the polarity in SD coating. However further addition of dammar, the adhesion of SD is reduced and this could be due to the coating stress which has developed during film formation that acted against adherence. According to Perera (1996) and Piens and Deurwaerder (2001), further increased in polarity and cross-link density, it will lead to development of coating stress and resulted in detachment of the coating.

\section{CONCLUSION}

Adhesion of modified Silicone-Dammar on aluminum q-panel was evaluated using cross hatch test, impact test and pull off test. Nano-indentation test was performed for determination of the hardness of the coating. It was found that $15 \mathrm{wt}$ \% of dammar (SD15) shows good adhesion and also demonstrate the lowest hardness value and therefore SD15 is soft and the most flexible polymer coating.

\section{ACKNOWLEDGEMENT}

The researchers would like to thank Research Management Institute, RMI University Technology
MARA and E-Science grant from Ministry of Higher Education (MOHE) of Malaysia for their financial support.

\section{REFERENCES}

Car, T., N. Radic, P. Panjan, M. Cekada and A. Tonejc, 2009. Correlation between hardness and stress in Al-(Nb, Mo, Ta) thin films. J. Thin Solid Films, 517: 4605-4609. DOI: 10.1016/j.tsf.2009.03.172

ILSC, 2011. NDSU researchers develop biobased resin for coating technology. Industry Letter, SpecialChem.

Omar, N.M. and A.H. Ahmad, 2009. Characteristics of paint systems prepared from dammar with the addition of natural pigment. Polymers Adv. Technol., 20: 161-164. DOI: 10.1002/pat.1247

Pan, X. and D.C. Webster, 2011. Impact of structure and functionality of core polyol in highly functional biobased epoxy resins. Macromol. Rapid Commun., 32: 1324-1330. DOI: 10.1002/marc.201100215

Perera, D.Y., 1996. On adhesion and stress in organic coatings. Progress Organics Coat., 28: 21-23. DOI: 10.1016/0300-9440(95)00585-4

Piens, M. and H.D. Deurwaerder, 2001. Effect of coating stress on adherence and on corrosion prevention. Progress Organic Coat., 43: 18-24. DOI: 10.1016/S0300-9440(01)00243-0

Zakaria, R. and A.H. Ahmad, 2009. Adhesion and water repellent properties of nascent dammarsilicone thin film: A bio mimicry approach. Proceedings of the International Conference on Nanoscience and Nanotechnology, Nov. 18-21, AIP, Shah Alam, Selandor, Malaysia, pp: 166170. DOI: $10.1063 / 1.3160122$

Zhili, L., J.C.M. Brokken-Zijp and G.D. With, 2004. Determination of the elastic moduli of silicone rubber coatings and films using depth-sensing indentation. J. Polymer, 45: 5403-5406. DOI: 10.1016/j.polymer.2004.05.076 